\title{
ON A MODEL OF OSCILLATIONS OF A THIN FLAT PLATE WITH A VARIETY OF MOUNTS ON OPPOSITE SIDES
}

\author{
U.A. Iskakova, Institute of Mathematics and Mathematical Modelling, Almaty, \\ Kazakhstan, ulzada@list.ru
}

We consider a model case of stationary vibrations of a thin flat plate, one side of which is embedded, the opposite side is free, and the sides are freely leaned. In mathematical modeling there is a local boundary value problem for the biharmonic equation in a rectangular domain. Boundary conditions are given on all boundary of the domain. We show that the considered problem is self-adjoint. Herewith the problem is ill-posed. We show that the stability of solution to the problem is disturbed. Necessary and sufficient conditions of existence of the problem solution are found. Spaces of the ill-posedness of the considered problem are constructed.

Keywords: oscillations; thin flat plate; biharmonic equation; boundary value problem; ill-posed problem.

Introduction. The theory of vibrations of thin flat plates is well elaborated to the present moment. Mathematical problems related to formulation and justification of well-posedness of statement of problems for stationary and non-stationary models are investigated detailed enough. Questions of optimal controlling of these vibrations have been studied. However, the investigation of problems, in modelling of which ill-posed problems arise, is far from its completeness [1]. And in this case one need to consider different variants of mathematical models. One of the basic situations from the physical point of view are cases of plates with constant bending stiffness or plates of optimal weight. It is well-known that the modelling of stationary vibrations of such thin plates without application of additional loads leads to problems for the homogeneous biharmonic equation [2].

Problems of modelling of thin plates vibrations with various conditions of fixation on different sides (edges) of the plate are the most interesting cases. Frequently in practice there arise problems of modelling of vibrations of plates, boundaries of which consist of finite number of smooth arcs with part of them being clamped (embedded), and the rest of the arcs being in free leaning. Such conditions are permissible and the problems arising in their modelling are investigated rather detailed.

In the present paper we consider the mathematical model, which arises when one of the sides of the flat plate is free. The mathematical modelling leads to the problem for the homogeneous biharmonic equation with different boundary conditions on opposite boundaries. This problem appears to be ill-posed.

The most known example of an ill-posed boundary value problem is the Cauchy problem for the Laplace equation. In $\Omega=\{(x, t): 0<x<\pi, 0<t<T\}$ consider equation

$$
\triangle u \equiv u_{t t}(x, t)+u_{x x}(x, t)=0, \quad(x, t) \in \Omega,
$$

with boundary conditions

$$
\left.u\right|_{x=0}=0,\left.\quad u\right|_{x=\pi}=0, \quad 0 \leq t \leq T,
$$


and initial conditions

$$
\left.u\right|_{t=0}=\varphi_{1}(x),\left.\quad \frac{\partial u}{\partial t}\right|_{t=0}=\varphi_{2}(x), \quad 0 \leq x \leq \pi .
$$

The classic Hadamard example showing [3] the instability of the solution

$$
u_{k}(x, t)=\frac{\sin (k x) \sinh (k t)}{k^{2}}
$$

to the Cauchy problem for the Laplace equation (1) with boundary conditions (2) and initial conditions:

$$
\left.u\right|_{t=0}=0,\left.\frac{\partial u}{\partial t}\right|_{t=0}=\frac{1}{k} \sin (k x),
$$

with respect to small changes of initial data is well-known.

The prominent soviet mathematicians, academicians A.N. Tikhonov and M.M. Lavrent'ev, their disciples and followers proved that the Cauchy problem for the Laplace equation, and other ill-posed problems [4, 5] are conditionally well-posed. Moreover they suggested the regularization of these ill-posed problems.

In $[6,7]$ they obtained a necessary and sufficient condition for well-posedness of problem $(1)-(3)$ in the space $L_{2}(\Omega)$ using method of expansion with the help of the eigenfunctions of the mixed Cauchy problem for the Laplace equation with deviating argument. There was considered [8] a nonlocal boundary value problem for the biharmonic equation in a disk.

One of ill-posed boundary value problems for elliptic equations is the case when the part of the domain boundary is exempt from the boundary conditions. A part of the boundary $t=T, 0 \leq x \leq \pi$ is exempt from boundary conditions in the Cauchy problem considered above.

In the present paper we consider a local problem for an elliptic equation of the fourth order, ill-posedness of which is analogous to the ill-posedness of the Cauchy problem for the Laplace equation. Herewith boundary conditions are given on all boundary of the domain.

\section{Statement of the Problem}

Problem $C$. Find in $D=\{(x, y): 0<x<\pi, 0<y<l\}$ a solution to the biharmonic equation

$$
\triangle^{2} u \equiv u_{x x x x}(x, y)+2 u_{x x y y}(x, y)+u_{y y y y}(x, y)=0, \quad(x, y) \in D,
$$

satisfying boundary conditions in the first spatial variable $x$ :

$$
\left.u\right|_{x=0}=0,\left.\triangle u\right|_{x=0}=0 ;\left.\quad u\right|_{x=\pi}=0,\left.\triangle u\right|_{x=\pi}=0 ; \quad 0 \leq y \leq l ;
$$

and boundary conditions in the second spatial variable $y$ :

$$
\begin{gathered}
\left.u\right|_{y=0}=\varphi_{1}(x),\left.\frac{\partial u}{\partial y}\right|_{y=0}=\varphi_{2}(x), \quad 0 \leq x \leq \pi ; \\
\left.\triangle u\right|_{y=l}=\psi_{1}(x),\left.\quad \frac{\partial \triangle u}{\partial y}\right|_{y=l}=\psi_{2}(x), \quad 0 \leq x \leq \pi .
\end{gathered}
$$

Definition 1. The function $u \in C^{4}(D) \bigcap C^{3}(\bar{D})$ satisfying equation (4) and boundary conditions $(5)-(7)$ is called a classic solution to problem $C$. 
2. Instability of Solution. Similarly to the Hadamard example one can construct an instability example of classic solution to problem $C$. Indeed, by direct calculation it is easy to obtain that the function

$$
u_{k}(x, y)=\sin (k x)\left\{\frac{\cosh (k l) \sinh (k y)}{k^{4}}-t \frac{\cosh (k(l-y))}{k^{3}}\right\}
$$

is a solution to problem $C$ for biharmonic equation (4) with boundary conditions (5) and with conditions

$$
\begin{gathered}
\left.u\right|_{y=0}=0,\left.\quad \frac{\partial u}{\partial y}\right|_{y=0}=0, \quad 0 \leq x \leq \pi \\
\left.\triangle u\right|_{y=l}=0,\left.\quad \frac{\partial \triangle u}{\partial y}\right|_{y=l}=-\frac{2}{k} \sin k x, \quad 0 \leq x \leq \pi .
\end{gathered}
$$

It is easy to see that the boundary data tend to zero for $k \rightarrow \infty$, but the solution $u_{k}(x, y)$ does not tend to zero in any norm. Consequently, the solution to the problem is instable. Therefore the considered problem $C$ is ill-posed.

3. Symmetry and positivity of an operator of the problem. Consider the problem with homogeneous boundary conditions $(6)-(7)$ :

$$
\begin{gathered}
\left.u\right|_{y=0}=0,\left.\frac{\partial u}{\partial y}\right|_{y=0}=0,0 \leq x \leq \pi ; \\
\left.\triangle u\right|_{y=l}=0,\left.\frac{\partial \triangle u}{\partial y}\right|_{y=l}=0,0 \leq x \leq \pi .
\end{gathered}
$$

Let $L$ be an operator in $L_{2}(D)$ being a closure of the operator given by the differential expression

$$
L u \equiv u_{x x x x}(x, y)+2 u_{x x y y}(x, y)+u_{y y y y}(x, y), \quad(x, y) \in D
$$

on a linear manifold of functions $u \in C^{4}(D) \bigcap C^{3}(\bar{D})$ satisfying boundary conditions (5), $\left(6^{\prime}\right),\left(7^{\prime}\right)$.

Show that the operator $L$ is symmetric. Let $u, v \in D(L)$ be two arbitrary elements from the domain of the operator $L$. For these elements there exist corresponding sequences of smooth functions $u_{n}, v_{n} \in C^{4}(D) \bigcap C^{3}(\bar{D})$ satisfying boundary conditions $(5),\left(6^{\prime}\right),\left(7^{\prime}\right)$ such that

$$
\lim _{n \rightarrow \infty} u_{n}=u, \lim _{n \rightarrow \infty} L u_{n}=L u ; \lim _{n \rightarrow \infty} v_{n}=v, \lim _{n \rightarrow \infty} L v_{n}=L v
$$

in $L_{2}(D)$.

Then by direct calculation we obtain for all $u, v \in D(L)$

$$
(L u, v)-(u, L v)=\lim _{n \rightarrow \infty}\left\{\left(L u_{n}, v_{n}\right)-\left(u_{n}, L v_{n}\right)\right\}=0
$$

Consequently the operator $L$ is symmetric. In this sense the boundary value problem (4) $-(7)$ is self-adjoint.

Similarly, for all $u \in D(L)$ we obtain $(L u, u)=\|\triangle u\|^{2} \geq 0$. Consequently the operator $L$ is positive. 
4. Construction of a Formal Solution of Problem (4) - (7). By $\omega_{k}(x)=$ $\sqrt{2 / \pi} \sin (k x), k=1,2, \ldots$ denote an orthonormal basis in $L_{2}(0, \pi)$. The solution to problem $(4)-(7)$ we represent in the form of an expansion into the orthogonal series

$$
u(x, y)=\sum_{k=1}^{\infty} \omega_{k}(x) v_{k}(y)
$$

By considering that series (8) converges and allows a term by term differentiation (the required number of times), we construct a formal solution to the problem. Substituting (8) to equation (4) and to the boundary conditions (6), (7), for $v_{k}(y)$ we obtain the problems

$$
\begin{gathered}
v_{k}^{(I V)}(y)-2 k^{2} v_{k}^{\prime \prime}(y)+k^{4} v_{k}(y)=0, \quad 0<y<l, \\
v_{k}(0)=\varphi_{1 k}, \quad v_{k}^{\prime}(0)=\varphi_{2 k}, \\
v_{k}^{\prime \prime}(l)-k^{2} v_{k}(l)=\psi_{1 k}, \quad v_{k}^{\prime \prime \prime}(l)-k^{2} v_{k}^{\prime}(l)=\psi_{2 k} .
\end{gathered}
$$

Here $\varphi_{i k}$ and $\psi_{i k}$ are the Fourier coefficients of the expansion according to the orthonormal basis $\left\{\omega_{k}(x)\right\}_{k=1}^{\infty}$ of the functions $\varphi_{i}(x)$ and $\psi_{i}(x)$ respectively:

$$
\varphi_{i}(x)=\sum_{k=1}^{\infty} \varphi_{i k} \omega_{k}(x), \quad \psi_{i}(x)=\sum_{k=1}^{\infty} \psi_{i k} \omega_{k}(x), \quad, i=1,2 .
$$

Equation (9) has a general solution

$$
v(y)=\left(C_{1} t+C_{2}\right) e^{k y}+\left(C_{3} t+C_{4}\right) e^{-k y} .
$$

We satisfy this solution to the boundary conditions (10), (11). Then we get the system of linear equations

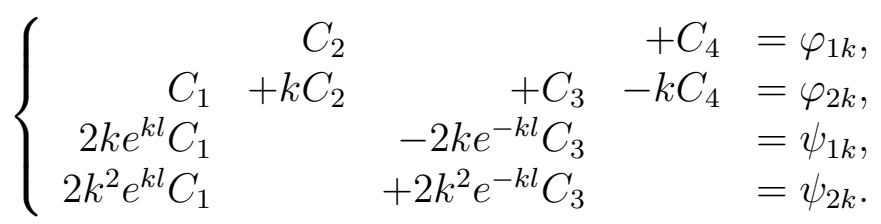

A determinant of this system equals to

$$
\Delta=16 k^{4} .
$$

Since $\Delta \geq 16$, then system (12) has a unique solution. By the direct calculation we get

$$
\begin{gathered}
C_{1}=\frac{1}{4 k^{2}} e^{-k l}\left\{k \psi_{1}+\psi_{2}\right\}, \\
C_{2}=\frac{1}{2 k}\left\{k \varphi_{1}+\varphi_{2}\right\}+\frac{1}{8 k^{2}}\left\{e^{k l}-e^{-k l}\right\} \psi_{1}-\frac{1}{8 k^{3}}\left\{e^{k l}+e^{-k l}\right\} \psi_{2}, \\
C_{3}=-\frac{1}{4 k^{2}} e^{k l}\left\{k \psi_{1}-\psi_{2}\right\}, \\
C_{4}=\frac{1}{2 k}\left\{k \varphi_{1}-\varphi_{2}\right\}-\frac{1}{8 k^{2}}\left\{e^{k l}-e^{-k l}\right\} \psi_{1}+\frac{1}{8 k^{3}}\left\{e^{k l}+e^{-k l}\right\} \psi_{2} .
\end{gathered}
$$


Consequently the solution to problem (9) - (11) has the form

$$
\begin{gathered}
v_{k}(y)=-\frac{y}{2 k} \sinh (k(l-y)) \psi_{1}+\frac{y}{2 k^{2}} \cosh (k(l-y)) \psi_{2}+ \\
+\left\{\varphi_{1}+\frac{1}{k} \varphi_{2}+\frac{1}{2 k^{2}} \sinh (k l) \psi_{1}-\frac{1}{2 k^{3}} \cosh (k l) \psi_{2}\right\} \sinh (k y) .
\end{gathered}
$$

Substituting the found result into (8), we get the formal solution to problem (4) - (7).

5. A Generalized Solution of Problem (4) - (7). Consider problem (4) - (7) in sense of a generalized solution. The most suitable notion for demonstrating conditions of stability is the notion of a strong solution.

Definition 2. The function $u \in L_{2}(D)$ is called a strong solution to problem (4) - (7), if there exists the sequence of the smooth functions $u_{n} \in C^{4}(\bar{D})$, such that $u_{n} \rightarrow u$ takes place in $L_{2}(D)$ for $n \rightarrow \infty$ and

$$
u_{n}(x, 0) \rightarrow \varphi_{1},\left(u_{n}\right)_{y}(x, 0) \rightarrow \varphi_{2},\left(\Delta u_{n}\right)(x, l) \rightarrow \psi_{1} \text { and }\left(\left(\Delta u_{n}\right)_{y}\right)(x, l) \rightarrow \psi_{2}
$$

in $L_{2}(0, \pi)$.

As the required sequence $u_{n}$, we choose a sequence of partial sums of the Fourier series:

$$
u_{n}(x, y)=\sum_{k=1}^{n} \omega_{k}(x) v_{k}(y) .
$$

If $\varphi_{i} \in L_{2}(0, \pi), \psi_{i} \in L_{2}(0, \pi), i=1,2$, then fulfillment of (14) is obvious. Consequently the existence of the strong solution to problem $(4)-(7)$ is equivalent to the convergence of the sequence $u_{n}$ in $L_{2}(D)$.

By virtue of the Parseval equality, the convergence of the sequence $u_{n}$ in $L_{2}(D)$ is equivalent to the convergence of the numerical series

$$
\sum_{k=1}^{\infty}\left\|v_{k}(y)\right\|_{L_{2}(0, l)}^{2}<\infty .
$$

6. A Criterion of Existence of a Solution to Problem (4) - (7). The main result of the paper is:

Theorem 1. Let $\varphi_{i} \in L_{2}(0, \pi), \psi_{i} \in L_{2}(0, \pi), i=1,2$. A strong solution to problem (4) - (7) exists if the numerical series

$$
\begin{gathered}
\sum_{k=1}^{\infty} \frac{1}{k^{3}} e^{2 k l}\left|k \varphi_{1 k}+\varphi_{2 k}\right|^{2}<\infty \\
\sum_{k=1}^{\infty} \frac{1}{k^{7}} e^{4 k l}\left|k \psi_{1 k}-\psi_{2 k}\right|^{2}<\infty
\end{gathered}
$$

converge. 
Proof. Solution (13) is represented in the form

$$
\begin{gathered}
v_{k}(y)=\frac{1}{8 k^{3}} e^{k l}\left(e^{k y}+(2 k y+1) e^{-k y}\right)\left(k \psi_{1}-\psi_{2}\right)+\frac{1}{2 k} e^{k y}\left(k \varphi_{1}+\varphi_{2}\right)+ \\
+\frac{1}{8 k^{3}} e^{-k l}\left((2 k y-1) e^{k y}+e^{-k y}\right)\left(k \psi_{1}+\psi_{2}\right)+\frac{1}{2 k} e^{-k y}\left(k \varphi_{1}-\varphi_{2}\right) .
\end{gathered}
$$

Taking into account that

$$
\begin{gathered}
\left\|e^{k y}+(2 k y+1) e^{-k y}\right\|^{2}=\frac{1}{2 k}\left\{e^{2 k l}+4\left(k^{2} l^{2}+k l+1\right)-\left(4 k^{2} l^{2}+8 k l+5\right) e^{-2 k l}\right\} \\
\left\|e^{k y}\right\|^{2}=\frac{1}{2 k}\left\{e^{2 k l}-1\right\}
\end{gathered}
$$

from (19) we obtain that conditions (17) and (18) are necessary and sufficient for fulfillment of $(16)$.

Conclusion. In the paper we consider one model of stationary vibrations of a thin flat plate, one side of which is embedded, the opposite side is free, and the sides are freely leaned. The mathematical modelling leads to a local boundary value problem for a biharmonic equation in a rectangular domain. Although boundary conditions in the problem are given on the whole boundary of the domain and it is self-adjoint, it is shown that the problem appears to be ill-posed. It is shown that the stability of the problem solution is violated. Necessary and sufficient conditions for existence of a solution to the investigated problem have been obtained. The spaces of the well-posedness of the considered problem have been constructed.

Acknowledgements. The author express es her gratitude to Prof. Tynysbek Kal'menov and Prof. Makhmud Sadybekov for valuable advices during the work. Research supported by the grant $0820 /$ GF4 of the Ministry of Education and Science of Republic of Kazakhstan.

\section{References}

1. Kabanikhin S.I. Inverse and Ill-Posed Problems. Siberian Electronic Mathematical Reports, 2010, vol. 7, pp. 380-394.

2. Komkov V. Optimal Control Theory for the Damping of Vibrations of Simple Elastic Systems. Berlin, Heidelberg, Springer, 1972.

3. Hadamard J. Le probleme de Cauchy et les equations aux derivees partialles lineaires hyperboliques. Paris, Hermann and Lie, 1932.

4. Lavrent'ev M.M. On the Cauchy Problem for Laplace Equation. Izvestiya Rossiiskoi Akademii Nauk. Seriya Matematicheskaya, 1956, vol. 20, no. 6, pp. 819-842. (in Russian)

5. Tikhonov A.N. Non-linear Equations of First Kind. Doklady akademii nauk SSSR, 1965, vol. 161, no. 5, pp. 1023-1026. (in Russian)

6. Kal'menov T.Sh., Iskakova U.A. Criterion for the Strong Solvability of the Mixed Cauchy Problem for the Laplace Equation. Doklady Mathematics, 2007, vol. 75, no. 3, pp. 370-373. DOI: $10.1134 / \mathrm{S} 1064562407030118$

7. Kal'menov T.Sh., Iskakova U.A. A Method for Solving the Cauchy Problem for the Laplace Equation. Doklady Mathematics, 2008, vol. 78, no. 3, pp. 874-876. DOI: $10.1134 / \mathrm{S} 1064562408060185$ 
8. Kal'menov T.Sh., Iskakova U.A. On a Boundary Value Problem for the Biharmonic Equation. AIP Conference Proceedings, 2015, vol. 1676, no. 020031. DOI: 10.1063/1.4930457.

\title{
ОБ ОДНОЙ МОДЕЛИ КОЛЕБАНИЙ ТОНКОЙ ПЛОСКОЙ ПЛАСТИНЫ С РАЗЛИЧНЫМИ ЗАКРЕПЛЕНИЯМИ ПРОТИВОПОЛОЖНЫХ СТОРОН
}

\section{У.А. Искакова}

\begin{abstract}
Рассматривается модель стационарньх колебаний тонкой плоской пластины, у которой одна сторона заделана, противоположная сторона свободна, а по боковым сторонам - свободное опирание. При математическом моделировании возникает локальная краевая задача для бигармонического уравнения в прямоугольной области. Краевые условия задаются на всей границе области. Показано, что рассматриваемая задача оказывается самосопряженной, и при этом некорректной. Показано, что нарушается устойчивость решения задачи. Найдены необходимые и достаточные условия существования решения исследуемой задачи. Построены пространства корректности рассматриваемой задачи.
\end{abstract}

Ключевые слова: колебания; тонкая плоская пластинка; бигармоническое уравнение; краевал задача; некорректная задача.

\section{Литература}

1. Кабанихин, С.И. Обратные и некорректные задачи / С.И. Кабанихин // Сибирские электронные математические известия. - 2010. - Т. 7. - С. 380-394.

2. Комков, В. Теория оптимального управления демпфированием колебаний простых упругих систем. - М.: Мир, 1972.

3. Hadamard, J. Le probleme de Cauchy et les equations aux derivees partialles lineaires hyperboliques / J. Hadamard. - Paris: Hermann and Lie, 1932.

4. Лаврентьев, М.М. О задаче Коши для уравнения Лапласа / М.М. Лаврентьев // Известия Российской академии наук. Серия математическая. - 1956. - Т. 20, № 6. - С. 819-842.

5. Тихонов, А.Н. О нелинейных уравнениях первого рода / А.Н. Тихонов // Доклады АН CCCP. - 1965. - Т. 161, № 5. - С. 1023-1026.

6. Кальменов, Т.Ш. Критерий сильной разрешимости смешанной задачи Коши для уравнения Лапласа / Т.Ш. Кальменов, У.А. Искакова // Доклады РАН. - 2007. - Т. 414, № 2. - С. 168-171.

7. Кальменов, Т.Ш. Об одном методе решения задачи Коши для уравнения Лапласа / Т.Ш. Кальменов, У.А. Искакова // Доклады РАН. - 2008. - Т. 423, № 4. - С. 730-732.

8. Kal'menov, T.Sh. On a Boundary Value Problem for the Biharmonic Equation / T.Sh. Kal'menov, U.A. Iskakova // AIP Conference Proceedings. - 2015. - V. 1676, № 020031.

Улзада Асиловна Искакова, кандидат физико-математических наук, доцент, ведущий научный сотрудник, руководитель проекта, Институт математики и математического моделирования (г. Алматы, Республика Казахстан), ulzada@list.ru.

Поступила в редакиию 28 февраля 2016 г. 